\title{
The Current State of Advanced Practice Provider Fellowships in Hospital Medicine: A Survey of Program Directors
}

\author{
David Klimpl, MD ${ }^{1 *}$; Thérèse Franco, MD, SFHM²; Sean Tackett, MD, MPH ${ }^{3}$; Tracy E Cardin ACNP, SFHM; \\ Brian Wolfe, MD'; Scott Wright, MD³; Flora Kisuule, MD, MPH, SFHM ${ }^{1}$
}

\begin{abstract}
${ }^{1}$ Division of Hospital Medicine, Johns Hopkins Bayview Medical Center, Baltimore, Maryland; ${ }^{2}$ Department of Medicine, Virginia Mason Medical Center, Seattle, Washington; ${ }^{3}$ Division of General Internal Medicine, Johns Hopkins Bayview Medical Center, Baltimore, Maryland; ${ }^{4}$ Adfinitas Health, Hanover, Maryland; ${ }^{5}$ Division of Hospital Medicine, University of Colorado Denver, Denver, Colorado.
\end{abstract}

BACKGROUND: Postgraduate training for advanced practice providers (APPs) is a growing field in hospital medicine. As hospital programs continue to benefit from highly trained physician assistants (PAs) and nurse practitioners (NPs), fellowship programs have become more prevalent. However, little is known about the number of active programs or how they prepare trainees.

OBJECTIVES: To describe the existing APP fellowships in hospital medicine, with a focus on program characteristics, rationale, curricula, and learner assessment.

METHODS: An electronic survey was distributed by e-mail to hospital medicine program directors in May 2018. The survey consisted of 25 multiple choice and short answer questions. Descriptive statistics were calculated utilizing Stata 13 for data analysis.

RESULTS: Of the 11 fellowships identified, 10 (91\%) of directors responded to the survey. Eighty percent of programs accept both NPs and PAs and $80 \%$ are between 12 and 13 months long. All programs cite "training and retaining" as the main driver for their creation and $90 \%$ were founded in institutions with existing physician residencies. Ninety percent of program curricula are informed by Society of Hospital Medicine resources. Despite these similarities, there was wide variation in both curricular content and APP fellow assessment.

CONCLUSION: APP fellowships in hospital medicine are quickly growing as a means to train and retain nonphysician hospitalists. While most programs accept similar types of applicants and share a common rationale for program development, there is little standardization in terms of curriculum or assessment. Further research may be valuable to characterize the best practices to guide the future of these fellowships. Journal of Hospital Medicine 2019;14:401-406. Published online first April 8, 2019. @ 2019 Society of Hospital Medicine ostgraduate training for physician assistants (PAs) and nurse practitioners (NPs) is a rapidly evolving field. It has been estimated that the number of these advanced practice providers (APPs) almost doubled between 2000 and 2016 (from 15.3 to 28.2 per 100 physicians) and is expected to double again by 2030 . $^{1}$ As APPs continue to become a progressively larger part of the healthcare workforce, medical organizations are seeking more comprehensive strategies to train and mentor them. ${ }^{2}$ This has led to the development of formal postgraduate programs, often called APP fellowships.

Historically, postgraduate APP fellowships have functioned to help bridge the gap in clinical practice experience between physicians and APPs. ${ }^{3}$ This gap is evident in hours of clinical training. Whereas NPs are generally expected to complete $500-1,500$ hours of clinical practice before graduating, ${ }^{4}$ and PAs are expected to complete 2,000 hours, ${ }^{5}$ most physicians will complete over 15,000 hours of clinical training by the end *Corresponding Author: David Klimpl, MD; E-mail: David.klimpl@gmail.com;
Telephone: 720-848-4289

Received: November 1, 2018; Revised: January 28, 2019;

Accepted: February 8, 2019

(C) 2019 Society of Hospital Medicine DOI 10.12788/jhm.3191 of residency. ${ }^{6}$ As increasing patient complexity continues to challenge the healthcare workforce, ${ }^{7}$ both the NP and the PA leadership have recommended increased training of graduates and outcome studies of formal postgraduate fellowships. ${ }^{8,9}$ In 2007, there were over 60 of these programs in the United States, ${ }^{10}$ most of them offering training in surgical specialties.

First described in 2010 by the Mayo Clinic, ${ }^{11}$ APP fellowships in hospital medicine are also being developed. These programs are built to improve the training of nonphysician hospitalists, who often work independently ${ }^{12}$ and manage medically complex patients. ${ }^{13}$ However, little is known about the number or structure of these fellowships. The limited understanding of the current APP fellowship environment is partly due to the lack of an administrative body overseeing these programs. ${ }^{14}$ The Accreditation Review Commission on Education for the Physician Assistant (ARC-PA) pioneered a model in 2007 for postgraduate PA programs, but it has been held in abeyance since 2014. ${ }^{15}$ Both the American Nurses Credentialing Center and the National Nurse Practitioner Residency and Fellowship Training Consortium have fellowship accreditation review processes, but they are not specific to hospital medicine. ${ }^{16}$ The Society of Hospital Medicine (SHM) has several resources for the training of APPs; ${ }^{17}$ however, it neither reviews nor accredits fellowship programs. Without standards, guidelines, or active 
TABLE. Characteristics of APP Hospital Medicine Fellowships

\begin{tabular}{|c|c|c|c|c|c|c|c|c|c|c|c|}
\hline Program & & A & B & c & D & E & $\mathbf{F}$ & G & H & I & J \\
\hline Years active & & 1 & 2 & 2 & 3 & 3 & 4 & 5 & 5 & 9 & $>10$ \\
\hline \multirow{3}{*}{$\begin{array}{l}\text { Program } \\
\text { context }\end{array}$} & Hospital beds & 403 & 338 & 452 & 400 & 681 & 350 & 455 & 900 & 765 & 213 \\
\hline & MD residency at institution? & Yes & Yes & Yes & Yes & Yes & No & Yes & Yes & Yes & Yes \\
\hline & Learn with residents? & Yes & Yes & Yes & Yes & No & No & No & No & Yes & Yes \\
\hline \multirow{4}{*}{$\begin{array}{l}\text { Program } \\
\text { features }\end{array}$} & Duration (months) & 12 & 12 & 12 & 18 & 6 & 12 & 12 & 12 & 13 & 12 \\
\hline & Use SHM core competencies? & No & Yes & Yes & Yes & No & No & No & Yes & Yes & Yes \\
\hline & What organization accredited the fellowship? & None & None & None & None & None & None & None & None & None & ARC-PA \\
\hline & Starting salary (in dollars) & $>70 \mathrm{~K}$ & $>70 \mathrm{~K}$ & $55-60 \mathrm{~K}$ & $55-60 \mathrm{~K}$ & $>70 \mathrm{~K}$ & $>70 \mathrm{~K}$ & $60-65 K$ & $65-70 \mathrm{~K}$ & $60-65 K$ & $55-60 \mathrm{~K}$ \\
\hline \multirow{4}{*}{$\begin{array}{l}\text { Fellow } \\
\text { characteristics }\end{array}$} & Eligible APPs & NP/PA & NP/PA & NP/PA & PA & NP/PA & NP/PA & NP/PA & NP/PA & NP/PA & PA \\
\hline & Fellows per class & $>5$ & 2 & 2 & 2 & $>5$ & $>5$ & 4 & 2 & $>5$ & 3 \\
\hline & Total alumni in the past five years & 3 & 3 & 3 & 2 & 20 & 6 & 12 & $>20$ & $>20$ & 14 \\
\hline & Female fellows in the past five years (\%) & 100 & 80 & 100 & 100 & 85 & 67 & 70 & 78 & 79 & 65 \\
\hline \multirow{3}{*}{$\begin{array}{l}\text { Postfellowship } \\
\text { employment }\end{array}$} & Is it implied that successful graduates will be retained? & No & Yes & No & No & Yes & Yes & No & Yes & No & No \\
\hline & Salary/bonus contingent on retention? & Yes & Yes & No & Yes & No & Yes & No & Yes & No & No \\
\hline & Alumni in last five years hired for full-time position (\%) & 100 & 75 & 100 & 100 & 96 & 100 & 75 & 71 & 86 & 90 \\
\hline \multirow{4}{*}{$\begin{array}{l}\text { Main driver(s) for } \\
\text { fellowship creation }\end{array}$} & Train and retain applicants & レ & $\boldsymbol{\nu}$ & $\boldsymbol{V}$ & $\boldsymbol{V}$ & レ & $\boldsymbol{V}$ & $\boldsymbol{\nu}$ & $\boldsymbol{\nu}$ & $\boldsymbol{\nu}$ & $\boldsymbol{r}$ \\
\hline & Build interprofessional team & $\nu$ & $\nu$ & & & & & & $\nu$ & $\nu$ & $r$ \\
\hline & Manage patient volume & $\boldsymbol{V}$ & $\boldsymbol{r}$ & & & & & & $\nu$ & & \\
\hline & Reduce overhead & & $\nu$ & & & & $\nu$ & & $\nu$ & & \\
\hline
\end{tabular}

Abbreviations: APP, advanced practice provider; ARC-PA, Accreditation Review Commission on Education for the Physician Assistant; IM, internal medicine; K, thousand; NP, nurse practitioner; PA, physician assistant; SHM, Society of Hospital Medicine.

accrediting bodies, APP fellowships in hospital medicine are poorly understood and are of unknown efficacy. The purpose of this study was to identify and describe the active APP fellowships in hospital medicine.

\section{METHODS}

This was a cross-sectional study of all APP adult and pediatric fellowships in hospital medicine, in the United States, that were identifiable through May 2018. Multiple methods were used to identify all active fellowships. First, all training programs offering a Hospital Medicine Fellowship in the ARC-PA and Association of Postgraduate PA Programs databases were noted. Second, questionnaires were given out at the NP/PA forum at the national SHM conference in 2018 to gather information on existing APP fellowships. Third, similar online requests to identify known programs were posted to the SHM web forum Hospital Medicine Exchange (HMX). Fourth, Internet searches were used to discover additional programs. Once those fellowships were identified, surveys were sent to their program directors (PDs). These surveys not only asked the PDs about their fellowship but also asked them to identify additional APP fellowships beyond those that we had captured. Once additional programs were identified, a second round of surveys was sent to their PDs. This was performed in an iterative fashion until no additional fellowships were discovered.

The survey tool was developed and validated internally in the AAMC Survey Development style ${ }^{18}$ and was influenced by prior validated surveys of postgraduate medical fellowships. ${ }^{10,19-21}$ Each question was developed by a team that had expertise in survey design (Wright and Tackett), and two survey design team members were themselves PDs of APP fellowships in hospital medicine (Kisuule and Franco). The survey was revised iteratively by the team on the basis of meetings and pilot testing with PDs of other programs. All qualitative or descriptive questions had a free response option available to allow PDs to answer the survey accurately and exhaustively. The final version of the survey was approved by consensus of all authors. It consisted of 25 multiple choice questions which were created to gather information about the following key areas of APP hospital medicine fellowships: fellowship and learner characteristics, program rationales, curricula, and methods of fellow assessment. 


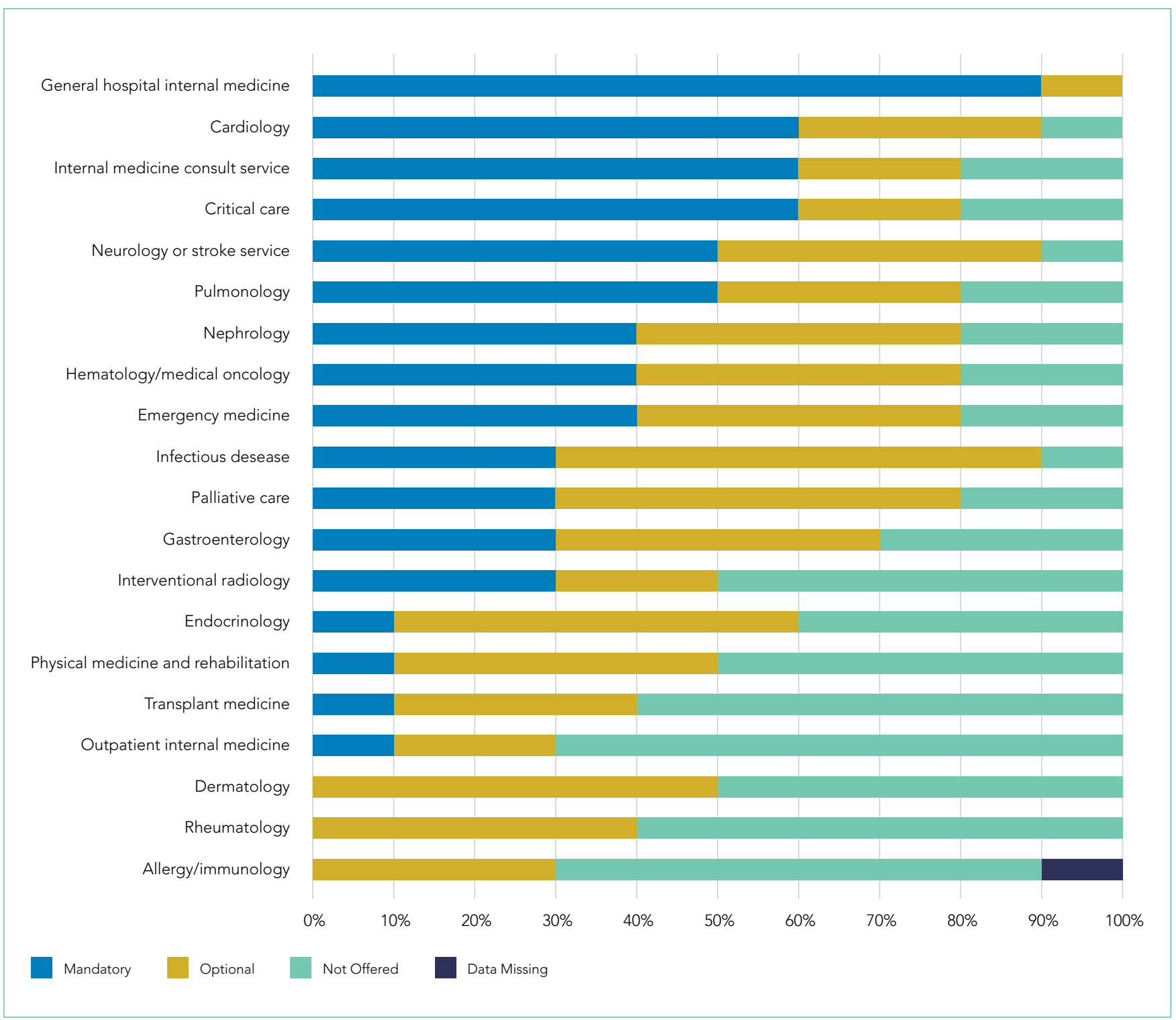

FIG 1. Educational Experiences for Advanced Practice Provider Hospital Fellowships: Clinical Rotations

A web-based survey format (Qualtrics) was used to distribute the questionnaire e-mail to the PDs. Follow up e-mail reminders were sent to all nonresponders to encourage full participation. Survey completion was voluntary; no financial incentives or gifts were offered. IRB approval was obtained at Johns Hopkins Bayview (IRB number 00181629). Descriptive statistics (proportions, means, and ranges as appropriate) were calculated for all variables. Stata 13 (StataCorp. 2013. Stata Statistical Software: Release 13. College Station, Texas. StataCorp LP) was used for data analysis.

\section{RESULTS}

In total, 11 fellowships were identified using our multimethod approach. We found four (36\%) programs by utilizing existing online databases, two (18\%) through the SHM questionnaire and HMX forum, three (27\%) through internet searches, and the remaining two $(18 \%)$ were referred to us by the other PDs who were surveyed. Of the programs surveyed, 10 were adult programs and one was a pediatric program. Surveys were sent to the PDs of the 11 fellowships, and all but one of them (10/11, 91\%) responded. Respondent programs were given alphabetical designations A through J (Table).

\section{Fellowship and Individual Characteristics}

Most programs have been in existence for five years or fewer. Eighty percent of the programs are about one year in duration; two outlier programs have fellowship lengths of six months and 18 months. The main hospital where training occurs has a mean of 496 beds (range 213 to 900). Ninety percent of the hospitals also have physician residency training programs. Sixty percent of programs enroll two to four fellows per year while $40 \%$ enroll five or more. The salary range paid by the programs is $\$ 55,000$ to $>\$ 70,000$, and half the programs pay more than $\$ 65,000$. 


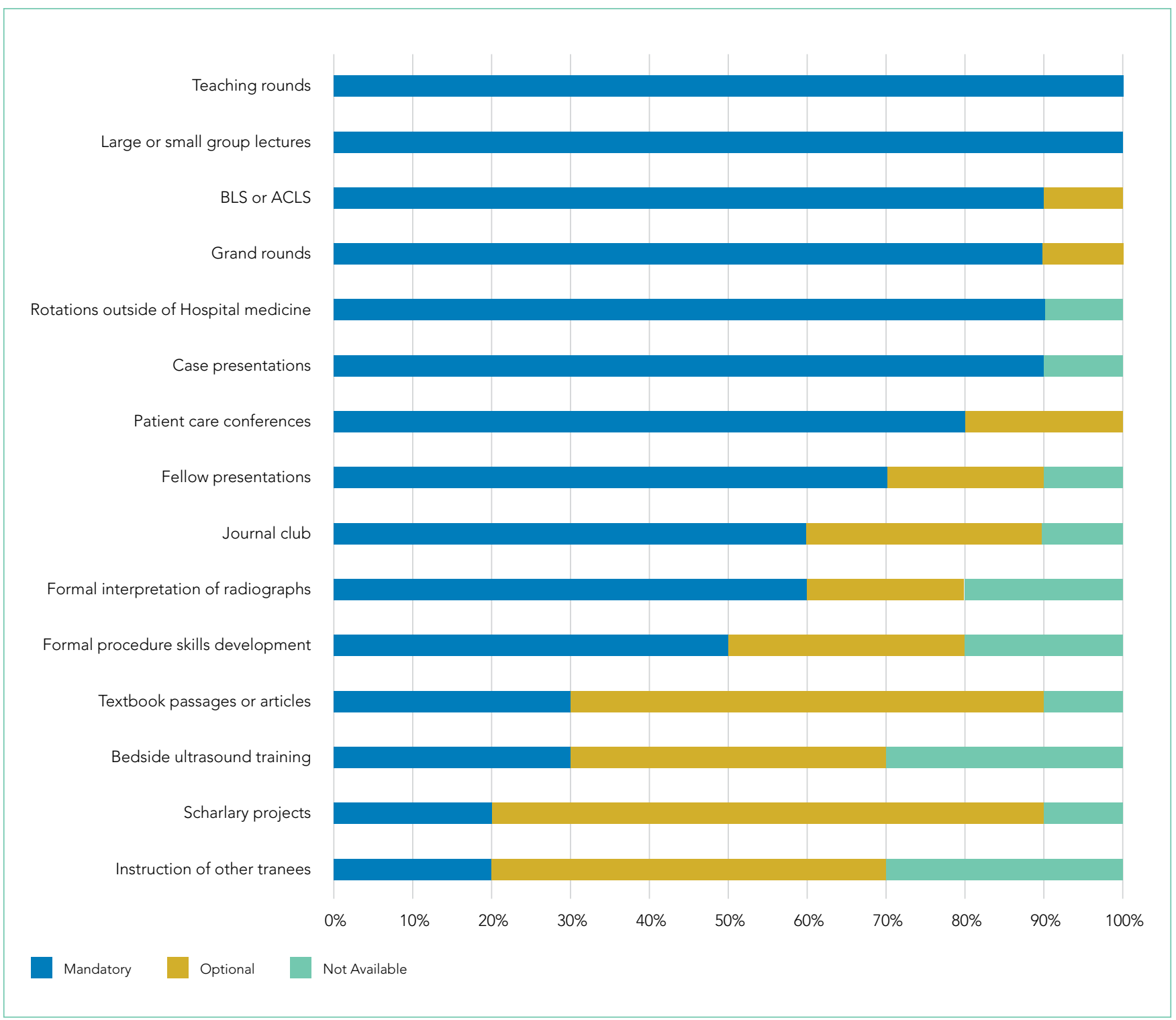

FIG 2. Educational Experiences for Advanced Practice Provider Hospital Fellowships: Learning Formats

The majority of fellows accepted into APP fellowships in hospital medicine are women. Eighty percent of fellows are 26-30 years old, and $90 \%$ of fellows have been out of NP or PA school for one year or less. Both NP and PA applicants are accepted in $80 \%$ of fellowships.

\section{Program Rationales}

All programs reported that training and retaining applicants is the main driver for developing their fellowship, and $50 \%$ of them offer financial incentives for retention upon successful completion of the program. Forty percent of PDs stated that there is an implicit or explicit understanding that successful completion of the fellowship would result in further employment. Over the last five years, $89 \%$ (range: $71 \%-100 \%$ ) of graduates were asked to remain for a full-time position after program completion.

In addition to training and retention, building an interprofessional team (50\%), managing patient volume (30\%), and reducing overhead (20\%) were also reported as rationales for program development. The majority of programs (80\%) have fellows bill for clinical services, and five of those eight programs do so after their fellows become more clinically competent.

\section{Curricula}

Of the nine adult programs, $67 \%$ teach explicitly to SHM core competencies and $33 \%$ send their fellows to the SHM NP/PA Boot Camp. Thirty percent of fellowships partner formally with either a physician residency or a local PA program to develop educational content. Six of the nine programs with active physician residencies, including the pediatric fellowship, offer shared educational experiences for the residents and APPs.

There are notable differences in clinical rotations between the programs (Figure 1). No single rotation is universally required, although general hospital internal medicine is required in all adult fellowships. The majority (80\%) of programs offer at least 
one elective. Six programs reported mandatory rotations outside the department of medicine, most commonly neurology or the stroke service (four programs). Only one program reported only general medicine rotations, with no subspecialty electives.

There are also differences between programs with respect to educational experiences and learning formats (Figure 2). Each fellowship takes a unique approach to clinical instruction; teaching rounds and lecture attendance are the only experiences that are mandatory across the board. Grand rounds are available, but not required, in all programs. Ninety percent of programs offer or require fellow presentations, journal clubs, reading assignments, or scholarly projects. Fellow presentations $(70 \%)$ and journal club attendance $(60 \%)$ are required in more than half the programs; however, reading assignments (30\%) and scholarly projects (20\%) are rarely required.

\section{Methods of Fellow Assessment}

Each program surveyed has a unique method of fellow assessment. Ninety percent of the programs use more than one method to assess their fellows. Faculty reviews are most commonly used and are conducted in all rotations in $80 \%$ of fellowships. Both self-assessment exercises and written examinations are used in some rotations by the majority of programs. Capstone projects are required infrequently (30\%).

\section{DISCUSSION}

We found several commonalities between the fellowships surveyed. Many of the program characteristics, such as years in operation, salary, duration, and lack of accreditation, are quite similar. Most fellowships also have a similar rationale for building their programs and use resources from the SHM to inform their curricula. Fellows, on average, share several demographic characteristics, such as age, gender, and time out of schooling. Conversely, we found wide variability in clinical rotations, the general teaching structure, and methods of fellow evaluation.

There have been several publications detailing successful individual APP fellowships in medical subspecialties, ${ }^{22}$ psychiatry, ${ }^{23}$ and surgical specialties, ${ }^{24}$ all of which describe the benefits to the institution. One study found that physician hospitalists have a poor understanding of the training PAs undergo and would favor a standardized curriculum for PA hospitalists. ${ }^{25} \mathrm{An}$ other study compared all PA postgraduate training programs in emergency medicine; ${ }^{19}$ it also described a small number of relatively young programs with variable curricula and a need for standardization. Yet another paper ${ }^{10}$ surveyed postgraduate PA programs across all specialties; however, that study only captured two hospital medicine programs, and it was not focused on several key areas studied in this paper-such as the program rationale, curricular elements, and assessment.

It is noteworthy that every program surveyed was created with training and retention in mind, rather than other factors like decreasing overhead or managing patient volume. Training one's own APPs so that they can learn on the job, come to understand expectations within a group, and witness the culture is extremely valuable. From a patient safety standpoint, it has been documented that physician hospitalists straight out of residency have a higher patient mortality compared with more experienced providers. ${ }^{26}$ Given the findings that on a national level, the majority of hospitalist NPs and PAs practice autonomously or somewhat autonomously, ${ }_{1}^{12}$ it is reasonable to assume that similar trends of more experienced providers delivering safer care would be expected for APPs, but this remains speculative. From a retention standpoint, it has been well described that high APP turnover is often due to decreased feelings of competence and confidence during their transition from trainees to medical providers. ${ }^{27}$ APPs who have completed fellowships feel more confident and able to succeed in their field. ${ }^{28}$ To this point, in one survey of hospitalist PAs, almost all reported that they would have been interested in completing a fellowship, even it meant a lower initial salary. ${ }^{29}$

Despite having the same general goals and using similar national resources, our study reveals that APP fellows are trained and assessed very differently between programs. This might represent an area of future growth in the field of hospitalist APP education. For physician learning, competency-based medical education (CBME) has emerged as a learner centric, outcomes-based model of teaching and assessment that emphasizes mastery of skills and progression through milestones. ${ }^{30}$ Both the $\mathrm{ACGME}^{31}$ and the $\mathrm{SHM}^{32}$ have described core competencies that provide a framework within CBME for determining readiness for independent practice. While we were not surprised to find that each fellowship has its own unique method of determining readiness for practice, these findings suggest that graduates from different programs likely have very different skill sets and aptitude levels. In the future, an active accrediting body could offer guidance in defining hospitalist APP core competencies and help standardize education.

Several limitations to this study should be considered. While we used multiple strategies to locate as many fellowships as possible, it is unlikely that we successfully captured all existing programs, and new programs are being developed annually. We also relied on self-reported data from PDs. While we would expect PDs to provide accurate data, we could not externally validate their answers. Additionally, although our survey tool was reviewed extensively and validated internally, it was developed de novo for this study.

\section{CONCLUSION}

APP fellowships in hospital medicine have experienced marked growth since the first program was described in 2010. The majority of programs are 12 months long, operate in existing teaching centers, and are intended to further enhance the training and retention of newly graduated PAs and NPs. Despite their similarities, fellowships have striking variability in their methods of teaching and assessing their learners. Best practices have yet to be identified, and further study is required to determine how to standardize curricula across the board.

\section{Acknowledgments}

The authors thank all program directors who responded to the survey.

Disclosures: The authors report no conflicts of interest. 
Funding: This project was supported by the Johns Hopkins School of Medicine Biostatistics, Epidemiology and Data Management (BEAD) Core. Dr. Wright is the Anne Gaines and G. Thomas Miller Professor of Medicine, which is supported through the Johns Hopkins' Center for Innovative Medicine

\section{References}

1. Auerbach DI, Staiger DO, Buerhaus PI. Growing ranks of advanced practice clinicians - implications for the physician workforce. N Engl J Med. 2018;378(25):2358-2360. doi: 10.1056/nejmp1801869.

2. Darves B. Midlevels make a rocky entrance into hospital medicine. Todays Hospitalist. 2007;5(1):28-32.

3. Polansky M. A historical perspective on postgraduate physician assistant education and the association of postgraduate physician assistant programs J Physician Assist Educ. 2007;18(3):100-108. doi: 10.1097/01367895-2007 18030-00014.

4. FNP \& AGNP Certification Candidate Handbook. The American Academy of Nurse Practitioners National Certification Board, Inc; 2018. https://www. aanpcert.org/resource/documents/AGNP FNP Candidate Handbook.pdf. Accessed December 20, 2018

5. Become a PA: Getting Your Prerequisites and Certification. AAPA. https:// www.aapa.org/career-central/become-a-pa/. Accessed December 20, 2018.

6. ACGME Common Program Requirements. ACGME; 2017. https://www.acgme.org/Portals/0/PFAssets/ProgramRequirements/CPRs_2017-07-01.pdf. Accessed December 20, 2018

7. Committee on the Learning Health Care System in America; Institute of Medicine, Smith MD, Smith M, Saunders R, Stuckhardt L, McGinnis JM. Best Care at Lower Cost: The Path to Continuously Learning Health Care in America. Washington, DC: National Academies Press; 2013.

8. The Future of Nursing LEADING CHANGE, ADVANCING HEALTH. THE NATIONAL ACADEMIES PRESS; 2014. https://www.nap.edu/read/12956/ chapter/1. Accessed December 16, 2018.

9. Hussaini SS, Bushardt RL, Gonsalves WC, et al. Accreditation and implications of clinical postgraduate pa training programs. JAAPA. 2016:29:1-7. doi: 10.1097/01.jaa.0000482298.17821.fb.

10. Polansky M, Garver GJH, Hilton G. Postgraduate clinical education of physician assistants. J Physician Assist Educ. 2012;23(1):39-45. doi: 10.1097/01367895-201223010-00008.

11. Will KK, Budavari Al, Wilkens JA, Mishark K, Hartsell ZC. A hospitalist postgraduate training program for physician assistants. J Hosp Med. 2010;5(2):9498. doi: 10.1002/jhm.619.

12. Kartha A, Restuccia JD, Burgess JF, et al. Nurse practitioner and physician assistant scope of practice in 118 acute care hospitals. J Hosp Med. 2014;9(10):615-620. doi: 10.1002/jhm.2231.

13. Singh S, Fletcher KE, Schapira MM, et al. A comparison of outcomes of general medical inpatient care provided by a hospitalist-physician assistant model vs a traditional resident-based model. J Hosp Med. 2011;6(3):122-130. doi: 10.1002/jhm.826.

14. Hussaini SS, Bushardt RL, Gonsalves WC, et al. Accreditation and implications of clinical postgraduate PA training programs. JAAPA. 2016;29(5):1-7. doi: 10.1097/01.jaa.0000482298.17821.fb.

15. Postgraduate Programs. ARC-PA. http://www.arc-pa.org/accreditation/ postgraduate-programs. Accessed September 13, 2018.

16. National Nurse Practitioner Residency \& Fellowship Training Consortium: Mission. https://www.nppostgradtraining.com/About-Us/Mission. Accessed September 27, 2018.

17. NP/PA Boot Camp. State of Hospital Medicine | Society of Hospital Medicine. http://www.hospitalmedicine.org/events/nppa-boot-camp. Accessed September 13, 2018

18. Gehlbach $\mathrm{H}$, Artino Jr AR, Durning SJ. AM last page: survey development guidance for medical education researchers. Acad Med. 2010;85(5):925. doi: 10.1097/ACM.0b013e3181dd3e88." Accessed March 10, 2018.

19. Kraus C, Carlisle T, Carney D. Emergency Medicine Physician Assistant (EMPA) post-graduate training programs: program characteristics and training curricula. West J Emerg Med. 2018;19(5):803-807. doi: 10.5811/westjem.2018.6.37892.

20. Shah NH, Rhim HJH, Maniscalco J, Wilson K, Rassbach C. The current state of pediatric hospital medicine fellowships: A survey of program directors. J Hosp Med. 2016;11(5):324-328. doi: 10.1002/jhm.2571.

21. Thompson BM, Searle NS, Gruppen LD, Hatem CJ, Nelson E. A national survey of medical education fellowships. Med Educ Online. 2011;16(1):5642. doi: 10.3402/meo.v16i0.5642.

22. Hooker R. A physician assistant rheumatology fellowship. JAAPA. 2013;26(6):49-52. doi: 10.1097/01.jaa.0000430346.04435.e4

23. Keizer T, Trangle M. the benefits of a physician assistant and/or nurse practitioner psychiatric postgraduate training program. Acad Psychiatry. 2015;39(6):691-694. doi: 10.1007/s40596-015-0331-z.

24. Miller A, Weiss J, Hill V, Lindaman K, Emory C. Implementation of a postgraduate orthopaedic physician assistant fellowship for improved specialty training. JBJS Journal of Orthopaedics for Physician Assistants. 2017:1. doi: 10.2106/jbjs.jopa.17.00021.

25. Sharma P, Brooks M, Roomiany P, Verma L, Criscione-Schreiber L. physician assistant student training for the inpatient setting. J Physician Assist Educ. 2017;28(4):189-195. doi: 10.1097/jpa.0000000000000174.

26. Goodwin JS, Salameh H, Zhou J, Singh S, Kuo Y-F, Nattinger AB. Association of hospitalist years of experience with mortality in the hospitalized medicare population. JAMA Intern Med. 2018;178(2):196. doi: 10.1001/jamainternmed.2017.7049.

27. Barnes $\mathrm{H}$. Exploring the factors that influence nurse practitioner role transition. J Nurse Pract. 2015;11(2):178-183. doi: 10.1016/j.nurpra.2014.11.004

28. Will K, Williams J, Hilton G, Wilson L, Geyer H. Perceived efficacy and utility of postgraduate physician assistant training programs. JAAPA. 2016;29(3):4648. doi: 10.1097/01.jaa.0000480569.39885.c8.

29. Torok H, Lackner C, Landis R, Wright S. Learning needs of physician assistants working in hospital medicine. J Hosp Med. 2011;7(3):190-194. doi: 10.1002/jhm.1001.

30. Cate $\bigcirc$. Competency-based postgraduate medical education: past, present and future. GMS J Med Educ. 2017:34(5). doi: 10.3205/zma001146.

31. Exploring the ACGME Core Competencies (Part 1 of 7). NEJM Knowledge. https://knowledgeplus.nejm.org/blog/exploring-acgme-core-competencies/. Accessed October 24, 2018.

32. Core Competencies. Core Competencies | Society of Hospital Medicine. http://www.hospitalmedicine.org/professional-development/core-competencies/. Accessed October 24, 2018. 